Jurnal Keperawatan Silampari

Volume 2, Nomor 1, Desember 2018

e-ISSN : 2581-1975

p-ISSN : 2597-7482

DOI : https://doi.org/10.31539/jks.v2i1.342

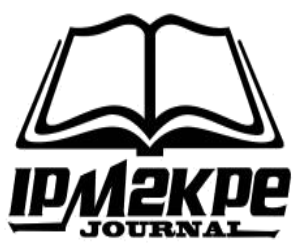

\title{
PERBEDAAN EFEKTIVITAS TEKNIK RELAKSASI NAFAS DALAM DAN KOMPRES HANGAT DALAM PENURUNAN NYERI DYSMENORHEA
}

\author{
Arni Wianti' ${ }^{1}$ Maulida Miftahul Karimah ${ }^{2}$ \\ Program Studi Keperawatan, STIKES YPIB Majalengka ${ }^{1,2}$ \\ arnie5sg@gmail.com ${ }^{1}$
}

\begin{abstract}
ABSTRAK
Penelitian ini bertujuan untuk mengetahui perbedaan efektivitas teknik relaksasi nafas dalam dan kompres hangat dalam penurunan nyeri dysmenorhea pada mahasiswi S1 Keperawatan tingkat II dan III STIKes YPIB Majalengka. Penelitian ini menggunakan metode eksperimental dengan pendekatan non equivalent control group. Hasil penelitian menggambarkan pada kelompok nafas dalam diperoleh nilai probabilitas $\rho$ $0,002<(0,05)$, sedangkan kelompok kompres hangat $\rho 0,000(0,05)$. Simpulan, terdapat perbedaan penurunan intensitas nyeri dysmenorhea saat dilakukan terapi relaksasi nafas dalam dan kompres hangat secara signifikan.
\end{abstract}

Kata Kunci: Dysmenorhea, Kompres Hangat, Relaksasi Nafas Dalam

\section{ABSTRACT}

This study aims to determine the differences in the effectiveness of deep breathing relaxation techniques and warm compresses in decreasing dysmenorhea pain in nursing students level II and III in STIKes YPIB Majalengka. This study uses an experimental method with a non equivalent control group approach. The results of the study illustrate that in the deep breath group a probability value of $\rho 0.002<(0.05)$, while the warm compress group $\rho 0.000$ (0.05). Conclusion, there is a significant difference in the decrease in the intensity of dysmenorrhea pain when deep breathing relaxation therapy and warm compresses are significant.

Keywords: Dysmenorhea, Warm Compresses, Deep Breath Relaxation 


\section{PENDAHULUAN}

Kesehatan reproduksi menurut badan kesehatan dunia atau World Health Organitation (WHO), yaitu kesejahteraan fisik, mental, dan sosial yang utuh tidak hanya bebas dari penyakit atau kecacatan, namun dalam semua aspek yang berkaitan dengan sistem reproduksi dan fungsi serta prosesnya (Taufan Nugroho, 2010).

Kesehatan reproduksi menurut Depkes (Departemen Kesehatan) RI (2000) merupakan suatu keadaan sehat menyeluruh mencakup asepk fisik, mental serta kedudukan sosial yang berkaitan dengan alat, fungsi serta proses reproduksi dan pemikiran kesehatan reproduksi tidak hanya kondisi yang bebas dari penyakit tetapi juga bagaimana seseorang dapat memiliki seksual yang aman dan memuaskan sebelum dan sesudah menikah.

Secara umum, kesehatan reproduksi adalah seberapa normal fungsi organ reproduksi. Jika organ tersebut terbentuk secara normal dan dapat berfungsi dengan baik, tentu dikatakan bahwa seseorang sudah mencapai kesehatan reproduksi yang optimal baik itu laki-laki ataupun perempuan. Reproduksi wanita merupakan sesuatu hal yang sangat kompleks, mulai dari organ reproduksi, pubertas yang ditandai dengan aktifnya siklus ovarium dan siklus menstruasi, fertilitas, hingga implantasi. Hormonhormon pada reproduksi wanita yang bekerja juga mempunyai ciriyang spesifik. Dengan mempelajari fisiologis reproduksi wanita, akan memudahkan kita dalam mempelajari infertilitas pada wanita yang tidak hamil, setiap bulan secara teratur mengeluarkan darah dari alat reproduksinya dinamakan haid (Yulia Fauziah, 2012).

Menurut Mansyur (2009) dan Manuaba (2009) menstruasi atau haid merupakan pelepasan dinding rahim (endometrium) yang disertai dengan pendarahan dan terjadi setiap bulannya. Seorang wanita sehat memiliki dua ovarium, masing-masing menyimpan sekitar 200.000-400.000 sel telur yang belum matang (folikel). Normalnya, hanya satu atau beberapa sel telur saja yang tumbuh setiap periode menstruasi. Apabila sel telur tidak dibuahi oleh sperma, maka lapisan dinding di bagian dalam dari rahim yang disiapkan untuk menempel hasil pembuahan akan terkelupas dan terjadilah perdarahan (menstruasi) (Oktasari, 2014).

Menstruasi atau haid adalah suatu bagian dari proses reguler yang mempersiapkan tubuh wanita untuk kehamilan setiap bulannya (Rahayuningrum, 2012). Menstruasi atau haid bisa dikatakan sebagai peristiwa pengeluaran mukus dan sel-sel epitel dari uterus secara periodik. Menstruasi umumnya, terjadi dengan siklus setiap bulan selama periode reproduksi, kecuali selama kehamilan dan menyusui. Siklus menstruasi ini akan muncul dalam 4 minggu atau 1 bulan, dimulai sejak hari pertama menstruasi sampai dengan hari pertama menstruasi berikutnya tiba. Namun demikian, tidak semua wanita mengalami siklus haid yang sama. Siklus haid ini terkadang datang lebih cepat ataupun lebih lambat dengan perbedaan kisaran 21 - 35 hari (Marianti, 2018).

Menstruasi pertama kali dialami perempuan sekitar usia 10 tahun, namun bisa juga lebih dini atau lebih lambat. Lamanya menstruasi biasanya terjadi antara 3 sampai dengan 5 hari, walaupun pada beberapa perempuan bisa saja mengalami masa menstruasi yang lebih panjang ataupun lebih pendek (Laila, 2011).

Setiap wanita memiliki pengalaman menstruasi yang berbeda-beda, tetapitidak sedikit dari mereka yang mendapatkan menstruasi disertai keluhan berupa dysmenorhea yang mengakibatkan rasa ketidaknyamanan. Dysmenorhea adalah rasa nyeri yang dirasakan di perut, yang berasal dari kram rahim dan terjadi selama menstruasi (El Manan, 2011). Secara umum, nyeri diartikan sebagai suatu keadaan yang tidak menyenangkan akibat terjadinya rangsangan fisik maupun dari serabut dalam serabut 
saraf dalam tubuh ke otak dan diikuti oleh reaksi fisik, fisiologis, maupun emosional (Hidayat 2008 dalam Padila, 2015). Nyeri yang dialami oleh pasien dipengaruhi oleh sejumlah faktor, termasuk pengalaman masa lalu dengan nyeri, usia, budaya dan pengharapan tentang penghilang nyeri. Faktor-faktor ini dapat meningkatkan atau menurunkan persepsi nyeri pasien, meningkat dan menurunnya toleransi terhadap nyeri dan pengaruh sikap respon terhadap nyeri (Suddarth, Brunner, 2001 dalam Padila, 2015).

Karakteristik dysmenorhea yaitu nyeri singkat sebelum awitan atau selama satu sampai beberapa hari selama menstruasi (Reeder et al, 2011). Nyeri ini biasanya lebih meningkat terjadi dari bulan keenam sampai tahun kedua setelah menstruasi pertama kali (Bobak, 2004; Oktasari, 2014).

Gejala-gejala nyeri menstruasi pada umumnya yaitu berupa rasa sakit datang secara tidak teratur, serta kadang-kadang ada kram di bagian belakang, menjalar ke kaki, pangkal paha, dan vulva (bagian luar alat kelamin perempuan). Nyeri menstruasi terjadi karena prostaglandin, yaitu zat yang menyebabkan otot rahim berkontraksi.

Pada sebagian perempuan, nyeri menstruasi dapat berupa nyeri yang samar, tetapi bagi sebagian yang lain dapat terasa kuat bahkan bisa membuat aktivitas terganggu (Laila, 2011). Menurut Bruner (1996) dysmenorhea dibagi menjadi dua yaitu dysmenorhea primer dan dysmenorhea sekunder. Dysmenorhea primer merupakan menstruasi yang sangat nyeri, tanpa patologis pelvis yang dapat diidentifikasi, dapat terjadi pada waktu menarche atau segera setelahnya (Dahlan, Syahminan, 2016). Suatu dysmenorhea dapat disebut dysmenorhea sekunder apabila penyebabnya berupa kelainan kandungan (El Manan, 2011).

Angka kejadian nyeri menstruasi di dunia rata-rata lebih dari $50 \%$ perempuan disetiap Negara mengalami dysmenorhea (Proverawati, Misaroh, 2009). Bahkan, menurut data WHO (2012) dalam Savitri (2015) didapatkan kejadian sebesar 1.769.425 jiwa (99\%) wanita mengalami dysmenorhea, dengan 10-15\% diantaranya mengalami dysmenorhea berat.

Prevalensi dysmenorhea di Amerika Serikat sangat tinggi. Hasil studi 90\% wanita mengalami dysmenorhea, 10-15\% diantaranya mengalami dysmenorhea berat yang menyebabkan wanita tidak mampu melakukan kegiatan sehari-hari. Biasanya, rasa nyeri mulai timbul sesaat sebelum atau selama menstruasi. Insiden terjadinya dysmenorhea rata-rata $40-80 \%$, dan 5-10\% diantaranya mengalami dysmenorhea berat sampai dysmenorhea yang tidak tertahankan (Morgan, Hamilton, 2009).

Studi Polatetal (2009) pada mahasiswi di Turki mengenai dysmenorhea primer mendapatkan hasil yang tak jauh berbeda yaitu sebesar $88 \%$ dan 45,3\% mengalami dysmenorhea disetiap periode menstruasi. Studi di Yordania, remaja putri yang haid menunjukkan $87,4 \%$ mengalami dysmenorhea primer dan $46 \%$ mengalami dysmenorhea tingkat berat (Razzak et al, 2016).

Sementara itu, prevalensi dysmenorrhea di Indonesia sekitar 50\% remaja putri mengalami dysmenorhea. Terdiri dari 54,89\% dysmenorhea primer dan 9,36\% dysmenorhea sekunder (Sari, dkk, 2013). Dinas Kesehatan Jawa Barat (2011), mengemukakan bahwa kejadian dysmenorhea pada remaja mencapai 35\% pada remaja SMA dan 27\% berada di beberapa Perguruan tinggi di Jawa Barat (Amalia, 2015).

Menurut Cakir, M et al, (2007) menemukan bahwa dysmenorhea merupakan gangguan menstruasi dengan prevalensi terbesar (89,5\%). Pada pengkajian terhadap penelitian-penelitian laindidapatkan prevalensi dysmenorhea bervariasi antara 15,8 - 
89,5\%, dengan prevalensi tertinggi pada remaja (Calis dkk, 2009; Hapsari, Anasari, 2015).

Penyebab terjadinya dysmenorhea tidak sepenuhnya diketahui, tetapi paling banyak ditemukan pada siklus ovulatorik fase sekres dimana pada fase ini adanya peningkatan kadar progesteron dan estrogen, namun hormon progesteron yang lebih dominan. Kemudian kadar keduanya mulai menurun secara perlahan karena korpus luteum mulai mengalami atresia. Kurang lebih selama 14 hari pasca ovulasi kadar progesteron dan estrogen cukup rendah, mengakibatkan sekresi gonadotropin meningkat dengan Follicle Stimulating Hormone (FSH) lebih dominan dari Luteinizing Hormone (LH). Meningkatnya LH akan mengakibatkan terjadinya peningkatan sekresi prostaglandin sehingga pada saat haid memicu timbulnya kontraksi kuat miometrium dan berkurangnya aliran darah ke endometrium sehingga terjadi pada nekrosis lapisan endometrium yang mengakibatkan timbulnya rasa nyeri pada saat haid (Anwar, 2011).

Dalam beberapa kasus, dysmenorhea dapat menyebabkan gangguan aktivitas sehari-hari jika tidak diatasi dengan baik. Dysmenorhea tidak hanya menyebabkan gangguan aktivitas, tetapi juga memberi dampak bagi fisik dan psikologis, misalnya cepat letih dan sering marah. Pada remaja, dysmenorheasering kali mengganggu aktivitas sekolah. Menurut Tangchai, remaja dengan dysmenorhea berat mendapat nilai yang rendah $(6,5 \%)$, menurunnya konsentrasi $(87,1 \%)$ dan absen dari sekolah $(80,6 \%)$ (Priscilla, dkk., 2012).

Dampak dysmenorrhea selain mengganggu aktivitas sehari-hari diantaranya menurunkan kinerja dan terjadi keluhan seperti mual, yang terkadang disertai muntah dan diare. Sebagian besar wanita menganggap nyeri haid sebagai hal yang biasa, mereka beranggapan 1-2 hari sakitnya akan hilang. Padahal nyeri haid hebat bisa menjadi tanda dangejala suatu penyakit misalnya endometriosis yang bisa mengakibatkan sulitnya mendapatkan keturunan (Prawirohardjo, 2008).

Secara umum penanganan dysmenorhea terbagi menjadi dua kategori yaitu pendekatan farmakologis dan non farmakologis. Secara farmakologis nyeri dapat ditangani dengan terapi analgesik, yang merupakan metode paling umum digunakan untuk menghilangkan nyeri. Untuk mengurangi rasa nyeri, bisa diberikan obat anti peradangan nonsteroid misalnya ibuprofen, naproxen dan asammefenamat. Walaupun analgesik dapat menghilangkan nyeri dengan efektif, namun penggunaan analgesik akan berdampak ketagihan dan akan memberikan efek samping obat yang berbahaya (Potter \& Perry, 2005; Priscilla, 2012). Sementara itu, pengobatan non farmakologis antara lain kompres hangat, teknik relaksasi seperti nafas dalam dan yoga.

Pada dysmenorhea primer, penanganan sering kali dilakukan dengan pengobatan non farmakologis, tetapi ada beberapa orang yang menggunakan pengobatan farmakologis. Sementara itu pada dysmenorhea sekunder, penanganan hanya bisa dilakukan dengan memberikan pengobatan farmakologis. Pengobatan dilakukan sesuai dengan penyakit yang menyertai (Priscilla, dkk., 2012).

Pengobatan non farmakologislebih dikenal dengan istilah terapi komplementer. Menurut Snyder, Lindquis (2002) perkembangan terapi komplementer akhir-akhir ini menjadi sorotan banyak negara. Pengobatan komplementer atau alternatif menjadi bagian penting dalam pelayanan kesehatan di dunia dan negara berkembang. Terapi komplementer yang dapat digunakan mengatasi nyeri diantaranya aromaterapi, hypnotherapy, terapi relaksasi nafas dalam, kompres air hangat, akupuntur dan distraksi (Padila, 2012). 
Pendekatan perawat dalam terapi komplementer mengacu pada prinsip holistik yang dimiliki oleh perawat. Prinsip holistik pada keperawatan ini perlu didukung oleh kemampuan perawat dalam menguasai berbagai bentuk terapi keperawatan, termasuk terapi komplementer. Penerapan terapi komplementer pada keperawatan kembali pada teori-teori yang mendasari praktik keperawatan. Misalnya, teori Rogers yang memandang manusia sebagai sistem terbuka, kompleks, mempunyai berbagai dimensi dan energi (Widyatuti, 2008).

Kompres air hangat menjadi salah satu dari beberapa terapi non farmakologis (komplementer)untuk menurunkan intensitas nyeri. Suhu panas diketahui bisa meminimalkan ketegangan otot. Setelah otot rileks, rasa nyeripun akan berangsur hilang (Laila, 2011). Kompres hangat dengan menggunakan botol kompres atau buli-buli yang telah diisi air hangat dan dikompreskan di daerah yang terasa nyeri selama 20 menit merupakan suatu terapi sederhana penghantar hangat yang bertujuan untuk mengurangi rasa nyeri, spasme dan iskemia (Arovah, 2010). Efek hangat yang dihasilkan oleh kompres hangat dapat meredakan iskemia dengan menurunkan kontraksi uterus dan melancarkan pembuluh darah sehingga dapat meredakan nyeri dengan menurunkan ketegangan dan memberikan efek berupa rasa nyaman (Bobak, 2004).

Price, Wilson (2006) mengemukakan bahwa penggunaan kompres hangat akan meningkatkan relaksasi ototjuga dapat mengurangi rasa nyeri akibat spasme yaitu kekakuan atau memberikan rasa hangat lokal. Panas akan meredakan iskemia yang menurunkan kontraksi juga meningkatkan sirkulasi. Kompres hangat dapat menyebabkan pelepasan endorfin tubuh sehingga memblok transmisi stimulasi nyeri. Menurut teori gate-control bahwa kompres hangat dapat mengaktifkan serat-serat nonnosiseptif yang berdiameter besar (A- $\alpha$ dan A- $\beta$ ) untuk "menutup gerbang" untuk serat-serat yang berdiameter kecil $(\mathrm{A}-\delta$ dan $\mathrm{C}$ ) yang berperan dalam menghantarkan nyeri, sehingga nyeri dapat dikurangi. Prinsip kerja kompres air hangat dapat dilakukan dengan menggunakan heating pad (bantal pemanas), kompres handuk, atau botol yang diisi air panas hangat tepat pada bagian yang terasa kram (Priscilla, 2012)

Selain kompres air hangat, teknik relaksasi juga banyak digunakan untuk penanganan nyeri. Relaksasi sangat diperlukan oleh tubuh. Saat kita terancam atau takut, tubuh kita memberikan dua macam reaksi, yaitu fight atau flight yang dicetuskan oleh hormon adrenalin. Smeltzer, Bare, (2002), mengemukakan bahwa relaksasi merupakan teknik pengendoran atau pelepasan ketegangan, misalnya, bernafas dalam dan pelan. Selain dapat menurunkan intensitas nyeri, teknik relaksasi nafas dalam juga dapat meningkatkan ventilasi paru dan meningkatkan oksigen darah (Priscilla, 2012).

Prinsip kerja daripada teknik relaksasi nafas dalam yakni dengan mengutamakan ketenangan pikiran. Teknik relaksasi nafas dalam bisa dilakukan dengan cara mengambil nafas dalam, tahan selama lima detik, lalu hembuskan secara perlahan (Laila, 2011).

Dari beberapa penelitian, diketahui bahwa teknik relaksasi nafas dalam dan kompres air hangat menunjukkan keefektifan dalam menurunkan nyeri saat menstruasi (dysmenorhea). Penelitian yang telah dilakukan oleh Chaudhuri, dkk di India (2012) menunjukkan hasil bahwa kompres air hangat efektif untuk menurunkan intensitas nyeri dysmenorhea. Sementara itu penelitian yang dilakukan oleh Siahaan, dkk di Bandung (2012) menunjukkan hasil bahwa teknik relaksasi efektif dalam menurunkan intensitas nyeri dysmenorhea. Penelitian yang dilakukan di Purwokerto oleh Hapsari, Anasari (2013) diperoleh hasil bahwa teknik relaksasi nafas dalam efektif menurunkan intensitas nyeri dysmenorhea. 
Penelitian lain yang dilakukan oleh Marni, dkk di Wonogiri (2013) menunjukkan hasil bahwa kompres air hangat lebih efektif menurunkan intensitas nyeri dysmenorhea dibandingkan dengan teknik relaksasi nafas dalam. Dan pada penelitian Priscilla, dkk di Padang (2012) menunjukkan hasil bahwa tidak terdapat perbedaan signifikan antara teknik relaksasi nafas dalam dan kompres hangat dalam menurunkan intensitas nyeri dysmenorhea.

Pemilihan tempat di STIKes YPIB Majalengka dikarenakan tingkat stressor pada mahasiswa lebih tinggi dibandingkan dengan siswa SMA. Stressor merupakan salah satu faktor yang dapat mempengaruhi peningkatan nyeri dysmenorhea.

Berdasarkan studi pendahuluan yang dilakukan pada 15-22 Maret 2017, diperoleh hasil bahwa sebagian besar mahasiswi DIII Kebidanan hanya mengalami dysmenorhea dengan intensitas nyeri ringan. Penanganan yang dilakukan pun cukup dengan istirahat atau mengoleskan minyak kayu putih saja. Sedangkan pada mahasiswi S1 Keperawatan, sebagian besar mahasiswi mengalami dysmenorhea dengan intensitas nyeri sedang. Penanganan yang dilakukan untuk mengatasi dysmenorhea memerlukan terapi komplementer. Angka kejadian dysmenorhea sendiri lebih banyak terjadi pada mahasiswi S1 Keperawatan tingkat II dan III dibandingkan dengan tingkat I. Sedangkan untuk tingkat IV, mahasiswi lebih sering berada di luar kampus untuk melakukan penelitian skripsi, sehingga tidak dapat dijadikan sebagai responden.

Berdasarkan hasil wawancara terhadap 20 mahasiswi S1 Keperawatan tingkat IIdan III STIKes YPIB Majalengka, diperoleh hasil 8 orang mengalami dysmenorhea ringan, 10 orang mengalami dysmenorhea sedang, dan 2 orang mengalami dysmenorhea berat. Sebagian besar mahasiswi mengalami dysmenorhea pada hari pertama menstruasi, dan sebagian lain masih mengalami dysmenorhea hingga menstruasi hari kedua. Beberapa mahasiswi mengatakan tidak dapat berkonsentrasi dalam pelajaran saat mengalami dysmenorhea. Mahasiswi dengan dysmenorhea berat bahkan sampai tidak bisa mengikuti pelajaran karena rasa mual dan muntah yang dirasakan.

Upaya mahasiswi dalam mengatasi dysmenorhea dilakukan dengan mengoleskan minyak kayu putih atau melakukan kompres hangat. Sementara itu, untuk mahasiswi yang mengalami dysmenorhea berat, penanganan dilakukan dengan meminum obat pengurang rasa sakit.

Tujuan dari penelitian ini yaitu untuk mengetahui perbedaan efektivitasterapi relaksasi nafas dalam dan kompres hangat dalam penurunan dysmenorhea pada mahasiswa S1 Keperawatan tingkat II dan III STIKes YPIB Majalengka tahun 2017.

\section{METODE PENELITIAN}

Jenis penelitian yang digunakan yaitu metode eksperimental dengan pendekatan non equivalent control group. Pendekatan ini menambahkan kelompok eksperimen kedua sebagai pembanding. Pada kelompok eksperimen, responden menerima perlakuan yang diikuti dengan pengukuran atau observasi. Dalam penelitian ini digunakan teknik pengambilan sampel accidental sampling. Jumlah anggota sampel yang digunakan dalam penelitian ini yaitu 20 , yakni 10 responden mendapat perlakuan teknik relaksasi nafas dalam dan 10 responden lainnya mendapat perlakuan kompres hangat. Instrumen penelitian untuk pengukuran intensitas nyeri menggunakan lembar observasi berupa "Skala intensitas nyeri numerik (Numeric Rating Scale) 0-10" (AHCPR) untuk mengukur intensitasi nyeri pre-test - post tes. 
HASIL PENELITIAN

Analisa Univariat

Tabel.1

Penurunan Intensitas Nyeri Dysmenorhea saat Dilakukan Terapi Relaksasi Nafas Dalam

\begin{tabular}{llllll}
\hline Intensitas Nyeri & & $\mathrm{N}$ & Mean & $\begin{array}{l}\text { Std. } \\
\text { Deviation }\end{array}$ & Std. Error Mean \\
\hline Kelompok & Pre Test & 10 & 6.40 & 1.34 & 0.42 \\
Nafas Dalam & Post Test & 10 & 4.10 & 1.10 & 0.34 \\
\hline
\end{tabular}

Berdasarkan tabel1 dapat dilihat bahwa intensitas nyeri dysmenorhea mahasiswi sebelum responden diberikan perlakuan terapi relaksasi nafas dalam dengan rata-rata intensitas nyeri 6,4 (kategori sedang), dan setelah responden diberi perlakuan terapi relaksasi nafas dalam rata-rata intensitas nyeri 4,1 (kategori sedang). Dengan demikian terdapat penurunan intensitas nyeri dysmenorhea saat dilakukan terapi relaksasi nafas dalam yakni sebesar 2,3 point.

Tabel. 2

Penurunan Intensitas Nyeri Dysmenorhea saat Dilakukan Terapi Kompres Hangat

\begin{tabular}{llllll}
\hline Intensitas Nyeri & & $\mathrm{N}$ & Mean & Std. Deviation & Std. Error Mean \\
\hline Kelompok & Pre Test & 10 & 6.60 & 1.17 & 0.37 \\
Kompres & Post Test & 10 & 3.30 & 1.25 & 0.39 \\
Hangat & & & & & \\
\hline
\end{tabular}

Berdasarkan tabel.2 dapat dilihat bahwa intensitas nyeri dysmenorhea mahasiswi sebelum responden diberi perlakuan terapi kompres hangat dengan rata-rata intensitas nyeri 6,6 (kategori sedang), dan setelah dilakukan terapi kompres hangat rata-rata responden mengalami intensitas nyeri menjadi 3,3 (kategori ringan). Dengan demikian, diperoleh penurunan intensitas nyeri dysmenorhea saat dilakukan terapi kompres hangat, yakni sebesar sebesar 3,3 point.

\section{Analisa Bivariat}

Tabel. 3

Hasil Uji Mann-Whitney Test Statistics ${ }^{\mathrm{b}}$

\begin{tabular}{lll}
\hline & $\begin{array}{l}\text { Kelompok Nafas } \\
\text { Dalam }\end{array}$ & Kompres hangat \\
\hline Mann-Whitney U & 10.500 & 2.000 \\
Wilcoxon W & 65.500 & 57.000 \\
\hline Z & -3.071 & -3.670 \\
Asymp. Sig. (2-tailed) & 0.002 & 0.000 \\
Exact Sig. [2*(1-tailed Sig.)] & $0.002^{\mathrm{a}}$ & $0.000^{\mathrm{a}}$
\end{tabular}

Berdasarkan hasil pengujian tingkat perbedaan dalam penurunan intensitas nyeri dysmenorhea saat dilakukan terapi relaksasi nafas dalam dan kompres hangat melalui uji Mann-Whitney $U$ dengan pada taraf signifikasi 5\% $\alpha(0,05)$, diperoleh nilai probabilitas kelompok nafas dalam $\rho 0,002<(0,05)$, sedangkankelompok kompres hangat $\rho 0,000<(0,05)$, berarti hipotesis nol ditolak, dinyatakan bahwa ada perbedaan 
penurunan intensitas nyeri dysmenorhea saat diberikan terapi relaksasi nafas dalam dan kompres hangat dapat diterima secara signifikan.

\section{PEMBAHASAN \\ Penurunan Intensitas Nyeri Dysmenorhea saat Diberi Terapi Relaksasi Nafas Dalam}

Berdasarkan temuan di lokasi penelitian, skala nyeri dysmenorhea yangbanyak dialami oleh mahasiswi S1 Keperawatan tingkat II dan III sebelum dilakukan perlakuan terapi relaksasi nafas dalam, diperoleh hasil rata-rata intensitas nyeri 6,4. Hasil ini menunjukkan bahwa intensitas nyeri dysmenorhea pada mahasiswi berada dalam kategori sedang (skala 4-6). Sedangkan setelah diberi terapi relaksasi nafas dalam, diperoleh hasil rata-rata intensitas nyeri 4,1 yang berada pada kategori nyeri sedang (skala 4-6). Dengan demikian terdapat penurunan intensitas nyeri dysmenorhea setelah diberi terapi relaksasi nafas dalam yakni sebesar 2,3 point.

Pada saat pertama kali dilakukan terapi relaksasi nafas dalam, tidak terdapat penurunan nyeri yang bermakna pada responden yang mengalami dysmenorhea. Hal ini terjadi karena pada saat pertama kali diberi teknik relaksasi nafas dalam, resoponden belum dapat berkonsentrasi. Menurut Yasui (2009) penurunan nyeri yang tidak signifikan dapat diperngaruhi adanya beberapa faktor. Seperti kurang berkonsentrasi saat melakukan teknik relaksasi. Karena jika kurang berkonsentrasi akan mengakibatkan gelombang otak alpha menjadi kurang kualitas dan kuantitasnya dalam upaya pengalihan perhatian yakni pengalihan nyeri.

Penurunan nyeri yang bermakna mulai terjadi saat responden melakukan teknik relaksasi nafas dalam lima kali secara berulang. Hal ini dapat terjadi karena responden telah dapat berkonsentrasi dan merasa rileks. Dalam kondisi tubuh rileks maka akan menghentikan produksi hormon adrenalin, semua hormon yang diperlukan saat stress. Karena hormon seks esterogen dan progesteron serta hormon stres adrenalin diproduksi dariblok kimiawi yang sama. Ketika kita ingin mengurangi stress, maka hal yang harus dilakukan adalah mengurangi produksi kedua hormon sekstersebut. Dalam hal ini, perlunya rileksasi untuk memberikan kesempatan bagi tubuh untuk memproduksi hormon yang penting untuk mendapatkan haid yang bebas dari nyeri (Potter, Perry, 2010).

Hasil penelitian inidapat mendukung teori Gate Control oleh Wall (1978) yang dikutip Fundamental Keperawatan (2010) bahwa implus nyeri akan dihantarkan saat sebuah pertahanan dibuka dan implus akan dihambat saat sebuah pertahanan tertutup. Dalam teori ini, yang memegang peranan penting adalah substansia gelatinosa, yang akan menutup dan membuka gerbang penghantar impuls nyeri. Upaya menutup pertahanan tersebut, maka dasar terapinya adalah untuk menghilangkan nyeri. Cara memblok ini dapat dilakukan yaitu dengan mengalihkan perhatian ataupun dengan tindakan relaksasi.

Terapi relaksasi nafas dalam jika dilakukan berulang-ulang akan menimbulkan rasa nyaman sehingga dapat meningkatkan toleransi terhadap nyeri. Jika toleransi terhadap nyeri meningkat, maka seseorang akan mampu beradaptasi dengan nyeri. Hal ini mendukung teori Kozier et al, (2010) yang menyatakan bahwa orang yang memiliki toleransi nyeri yang baik akan mampu beradaptasi terhadap nyeri dan memiliki mekanisme pada koping yang baik. Selain meningkatkan toleransi nyeri, rasa nyaman yang dirasakan paska dilakukan nafas dalam juga dapat meningkatkan ambang nyeri sehingga dengan meningkatnya ambang nyeri tersebut, maka nyeri yang terjadi berada 
pada skala 2 (nyeri sedang) menjadi skala 1 (nyeri ringan) setelah diberi terapi relaksasi nafas dalam (Priscilla, 2012).

Perbedaan yang bermakna pada skala nyeri haid yaitu sebelum dengan sesudah dilakukan relaksasi ternyata sesuai dengan teori yang menyatakan bahwa teknik relaksasi nafas dalam akan menurunkan intensitas nyeri adalah teori Huges (1995 dalam Ernawati, 2010) menurutnya dalam keadaan tertentu tubuh manusia dapat mengeluarkan opoid endogen yaitu endorfin dan enkefalin. Zat-zat tersebut, mempunyai sifat yang mirip seperti morfin dengan efek analgetik yang membentuk suatu "sistem penekan nyeri”.

Teknik relaksasi nafas dalam bisa dijadikan sebagai salah satu keadaan yang dapat menstimulus tubuh yang mengeluarkan opoid endogen sehingga akan terbentuk system penekan nyeri, akhirnya menyebabkan penurunan intensitas nyeri. Oleh karena itu,dapat terjadi perbedaan penurunan intensitas nyeri sebelum dengan sesudah diberi teknik relaksasi nafas dalam.

Akan tetapi, hasil penelitian ini lebih tinggi apabila dibandingkan dengan penelitian Marni, dkk yang dilakukan di Wonogiri (2014) yang menunjukkan hasil terdapat penurunan nyeri dyemsnorhea dengan penurunan nilai mean sebanyak 2,03 point. Tingkatan nyeri individu berbeda satu sama lain, begitu pula respon seseorang terhadap rasa nyeri itu sendiri. Hal ini mendukung teori Perry dan Potter (2010) yang menyatakan bahwa nyeri dapat dipengaruhi oleh beberapa faktor, di antaranya usia, perhatian, makna nyeri, pengalaman masa lalu, pekerjaan, pengetahuan, dan dukungan keluarga. Respon nyeri seseorang juga dipengaruhi oleh lingkungan, setiap tempat memiliki perbedaan dalam mengatasi nyeri. Menurut Muttaqin (2011), setiap sukudan nilai-nilai budaya, dapat mempengaruhi caraindividu mengatasi nyeri. Individu mempelajari apa yang diharapkan dan apa yang diterima oleh kebudayaan mereka. Hal ini meliputi bagaimana bereaksi terhadap nyeri.

Teknik relaksasi nafas dalam sebagai cara yang paling mudah dilakukan dalam mengontrol ataupun mengurangi nyeri. Teknik ini dengan mudah dapat dilakukan di rumah, di sekolah ataupun kampus. Seperti halnya teknik relaksasi lainnya, dan dengan menggunakan pengukuran skala nyeri numerik, responden dapat dengan mudah memberitahu skala nyeri yang dialaminya. Maka dari itu, peneliti menyarankan untuk menggunakan teknik relaksasi nafas dalam untuk menurunkan nyeri dysmenorhea.

\section{Penurunan Intensitas Nyeri Dysmenorhea saat Dilakukan Terapi Kompres Hangat}

Berdasarkan temuan di lokasi penelitian, skala nyeri dysmenorhea yangbanyak dialami oleh mahasiswi S1 Keperawatan tingkat II dan III sebelum dilakukan perlakuan terapi kompres hangat, diperoleh rata-rata intensitas nyeri 6,6. Hasil ini menunjukkan bahwa intensitas nyeri dysmenorhea pada mahasiswi berada pada kategori nyeri sedang (skala 4-6). Sedangkan setelah dilakukan terapi kompres hangat, rata-rata intensitas nyeri menjadi 3,3 dengan kategori nyeri ringan (skala 1-3). Dengan demikian, terdapat penurunan intensitas nyeri dysmenorhea setelah dilakukan terapi kompres hangat, yakni sebesar sebesar 3,3 point.

Responden mulai mengalami penurunan nyeri setelah diberikan kompres hangat pada 5 menit pertama. Pada beberapa menit selanjutnya, tingkat nyeri berangsur menurun. Hal tersebut terjadi kompres hangat dapat mengurangi neuron eferens didalam mentransmisikan tingkat nyeri menstruasi. Sejalan dengan Tamsuri (2007) yang mengemukakan bahwa penurunan nyeri disebabkan karena adanya impuls-impuls yang menekan rasa nyeri, sehingga rasa nyeri tersebut menjadi berkurang. Impuls-impuls 
tersebut yang merupakan suhu hangat pada bagian tubuh yang terasa sakit/nyeri adalah perut bagian bawah, pinggang bagian kanan dan kiri. Jika respon lokal, panas terjadi melalui stimulasi ujung saraf yang ada di dalam kulit dan sensitif terhadap suhu. Stimulasi ini mengirimkan impuls dari perifer menuju hipotalamus yang akan menyebabkan timbulnya kesadaran terhadap suhu lokal dan merangsang timbulnya respon adaptif untuk mempertahankan suhu dan kondisi normal tubuh.

Adanya perbedaan ini menunjukkan skala nyeri haid antara sebelum dan sesudah dilakukan tindakan kompres hangat mengalami perbedaan. Hal ini sesuai dengan pernyataan Potter dan Perry (2010) menyatakan bahwa kompres hangat adalah pengompresan dilakukan denganmempergunakan buli-buli panas yang dibungkus kain secara ditempatkan di area nyeri sehingga akan terjadi konduksi, dimana terjadi pemindahan panas dari buli-buli ke dalam tubuh, hal ini akan menyebabkan pelebaran pembuluh darah dan terjadi penurunan ketegangan otot, sehingga nyeri haid yang dirasakan akan berkurang atau hilang. Hal ini sesuai dengan penelitian Rahayuningrum (2012) yang mengatakan bahwa terdapat penurunan skala dysmenorhea pada remaja di SMAN 3 Padang pada kelompok yang mendapatkan kompres hangat.

Peningkatan suhu melalui kompres hangat dapat meredakan nyeri dengan menyingkirkan inflamasi. Hal ini didukung oleh Price, Wilson (2006) menyatakan bahwa panas dapat dialirkan melalui konduksi, konveksi, dan konversi. Nyeri yang disebabkan oleh spasme otot, memar, dan juga arthritis akan berespon baik terhadap peningkatan suhu karena dapat melebarkan pembuluh darah dan meningkatkan aliran darah lokal. Maka, peningkatan suhu yang disalurkan melalui kompres hangat akan meredakan nyeri dengan menyingkirkan produk inflamasi, seperti bradikinin, histamin dan prostaglandin akan menimbulkan rasa nyeri lokal (Oktasari, 2013).

Suhu panas juga dapat merileksasikan ketegangan otot dan mengurangi nyeri akibat spasme. Hal tersebut selaras dengan teori Price, Wilson (2006), yang menyatakan bahwa suhu panas diketahui dapat menurunkan rasa nyeri. Penggunaan kompres hangat dapat meningkatkan relaksasi otot-otot juga mengurangi nyeri akibat spasme serta memberikan rasa hangat lokal. Panas meredakan iskemia dengan menurunkan kontraksi dan meningkatkan sirkulasi. Kompres hangat dapat menyebabkan pelepasan endorfin tubuh sehingga memblok transmisi stimulasi nyeri (Priscilla, 2012).

Sementara itu menurut Kozier et al, (2010) panas merupakan pengobatan tradisional untuk meredakan rasa sakit dan nyeri. Suhu panas menyebabkan vasodilatasi dan meningkatkan aliran darah ke area yang terinfeksi, membawa oksigen, zat nutrisi, antibodi, dan leukosit.

Menurut Bobak (2005) terjadinya penurunan nyeri haid setelah diberikan kompres hangat akan menyebabkan iskemia teratasi dengan turunnya tingkat ketegangan uterus dan melancarkan peredaran darah sehingga nyeri yang dirasakan pada saat haid dapat berkurang dan berangsur menghilang. Sedangkan teori lain menurut Arovah (2010) kompres hangat yang diaplikasikan pada area yang nyeri selama 20 menit dapatmemberikan efek berupa rasa nyaman serta dapat merileksasikan tubuh secara umum, spasme, iskemia dan hipoksia sehingga intensitas nyeri yang dirasakan dapat berangsur menghilang.

Hasil penelitian ini lebih tinggi dibandingkan dengan hasil penelitianyang dilakukan oleh Gayatri Oktasari., dkk di Pekanbaru (2014) pada penelitian tersebut diperoleh hasil terdapat penurunan intensitas nyeri dysmenorhea penurunan nilai mean sebanyak 2,03 point. Hal ini terjadi karena pada penelitian yang dilakukan oleh Gayatri Oktasari, dkk karakeristik usia responden sekitar 12-14 tahun, sedangkan pada 
penelitian ini karakteristik usia responden sekitar 19-20 tahun. Menurut Muttaqin (2011) umur merupakan variabel yang mempengaruhi nyeri. Perbedaan perkembangan yang ditemukan antara kelompok usia dapat mempengaruhi bereaksi terhadap nyeri.

Beberapa hal yang mempengaruhi tingkatan nyeri seseorang. Setiap individu memiliki derajat nyeri yang berbeda satu sama lain, begitu pula respon seseorang terhadap rasa nyeri itu sendiri. Perry, Potter (2010), mengemukakan bahwa nyeri dapat dipengaruhi oleh beberapa faktor, di antaranya usia, perhatian, makna nyeri, pengalaman masa lalu, pekerjaan, pengetahuan, dan dukungan keluarga.

Setiap individu juga memiliki respon berbeda terhadap nyeri yang dirasakan. Terdapat perbedaan antara tempat yang satu dengan yang lain dalam mengatasi nyeri. Hal tersebut sesuai teori yang dikemukakan oleh Muttaqin (2011) yang menyatakan bahwa setiap sukudan nilai-nilai budaya mempengaruhi caraindividu mengatasi nyeri. Individu mempelajariapa yang diharapkan dan apa yang diterima olehkebudayaan mereka. Hal ini meliputi bagaimanabereaksi terhadap nyeri.

Terapi kompres hangat merupakan cara yang paling mudah dilakukan dalam mengontrol ataupun mengurangi nyeri. Selain mudah dilakukan, teknik kompres hangat juga tidak memerlukan biaya yang mahal dalam penerapannya. Pengukuran nyeri dapat menggunakan pengukuran skala nyeri numerik, responden dapat dengan mudah memberitahu skala nyeri yang dialaminya. Maka dari itu, peneliti menyarankan untuk menggunakan teknik kompres hangat untuk menurunkan nyeri dysmenorhea.

\section{Perbedaan Penurunan Intensitas Nyeri Dysmenorhea saat Dilakukan Terapi Relaksasi Nafas Dalam dan Kompres Hangat}

Dengan menggunakan uji Mann-Whitney U mengenai perbedaan antara relaksasi dan kompres dalam menurunkan skala nyeri menunjukkan hasil yang signifikasi, yakni $5 \% \propto(0,05)$, diperoleh nilai probabilitas kelompok nafas dalam $\rho 0,002<(0,05)$, sedangkankelompok kompres hangat $\rho$ 0,000(0,05), berarti hipotesis nol ditolak, dinyatakan bahwa ada perbedaan penurunan intensitas nyeri dysmenorhea saat dilakukan terapi relaksasi nafas dalam dan kompres hangat dapat diterima secara signifikan.

Pada penelitian ini 10 responden diberi terapi relaksasi nafas dalam dengan interval waktu 20 menit dan 10 responden diberikan terapi kompres hangat selama 20 menit pada saat mengalami dysmenorhea. Sebelum diberikan perlakuan terapi relaksasi nafas dalam maupun kompres hangat, peneliti terlebih dahulu melakukan pengukuran intensitas nyeri dysmenorhea. Setelah diberikan perlakuan, selanjutnya dilakukan kembali pengukuran intensitas nyeri dysmenorhea.

Penurunan nyeri pada penelitian ini cukup signifikan, yakni nilai mean untuk penurunan skala nyeri dysmenorhea pada responden yang dilakukan terapi relaksasi nafas dalam sebanyak 2,3 point. Sedangkan pada responden yang dilakukan terapi kompres hangat didapatkan nilai mean penurunan skala nyeri sebanyak 3,3 point. Hal ini menunjukkan bahwa pemberian terapi kompres hangat lebih efektif dalam menurunkan nyeri dibandingkan pemberian terapi relaksasi nafas dalam dengan selisih perbedaan 1 point.

Hasil penelitian ini sejalan dengan penelitian yang dilakukan oleh Lisa \& Dwi Purwanti (2013) tentang perbedaan keefektifan terapi kompres hangat dan aromaterapi dalam penurunan nyeri dysmenorhea. Hasil akhir menunjukkan bahwa terdapat perbedaan signifikan terhadap penurunan derajat nyeri dysmenorhea. Penelitian ini menunjukkan bahwa kompres hangat lebih efektif dibandingkan dengan metode 
aromaterapi. Hal tersebut terjadi karena kompres panas merupakan metode yang efektif dalam mengurangi nyeri atau kejang.

Pernyataan tersebut diperkuat oleh teori yang dikemukakan oleh Price, Wilson (2006) yang menyatakan bahwa suhu panas diketahui dapat menurunkan rasa nyeri. Penerapan kompres hangat akan meningkatkan relaksasi otot-otot juga mengurangi nyeri akibat spasme serta memberikan rasa hangat di daerah lokal. Panas meredakan iskemia dengan menurunkan kontraksi dan meningkatkan sirkulasi. Kompres hangat dapat menyebabkan pelepasan endorfin tubuh sehingga membentengi transmisi stimulasi nyeri (Priscilla, 2012).

Dalam penelitian ini, peneliti telah berusaha, akan tetapi masih ada beberapa kelemahan dan keterbatasan, yaitu: instrumen penelitian yang digunakan untuk mengukur nyeri dysmenorhea yang sifatnya subyektif, setiap individu berbeda dalammempersepsikan rasa nyeri, tergantung dari faktor yangmempengaruhi kondisi individu tersebut, padahal dalam penelitian ini peneliti tidak meneliti tentang faktorfaktor yang mempengaruhi rasa nyeri. Selain itu, penelitian ini kurang mendalam dalammenggali data, responden hanya menjawab sesuai instrumen yang dibagikan saja.

Teknik relaksasi nafas dalam dengan kompres hangat dapat digunakan untuk mengurangi nyeri dysmenorhea. Kedua teknik ini dapat mengurangi ketegangan otot yang dirasakan selama menstruasi. Selain itu, kedua teknik ini dapat dengan mudah dilakukan. Oleh karena itu, peneliti menyarankan untuk menggunakan teknik relaksasi nafas dalam dan kompres hangat sebagai salah satu alternatif penurunan nyeri dysmneorhea.

\section{SIMPULAN}

Intensitas nyeri dysmenorhea mahasiswi S1 Keperawatan tingkat II dan III STIKes YPIB Majalengka tahun 2017 sebelum dilakukan perlakuan terapi relaksasi nafas dalam dengan rata-rata intensitas nyeri 6,4 (kategori sedang), dan setelah diberi terapi relaksasi nafas dalam rata-rata intensitas nyeri 4,1 (kategori sedang). Intensitas nyeri dysmenorhea mahasiswi S1 Keperawatan tingkat II dan III STIKes YPIB Majalengka tahun 2017 sebelum dilakukan perlakuan terapi kompres hangat dengan rata-rata intensitas nyeri 6,6 (kategori sedang), dan setelah dilakukan terapi kompres hangat rata-rata intensitas nyeri menjadi 3,3 (kategori ringan). Terdapat perbedaan penurunan intensitas nyeri dysmenorhea saat dilakukan terapi relaksasi nafas dalam dan kompres hangat secara signifikan dengan pada taraf signifikasi $5 \% \alpha(0,05)$.

\section{SARAN}

1. Bagi Profesi Keperawatan. Memberikan kontribusi terhadap pengembangan kemandirian perawat dalam memberikan intervensi keperawatan, khususnya Keperawatan Maternitas dalam penanganan nyeri dysmenorhea.

2. Bagi Institusi. Sebagai masukan, agar dapat meningkatkan pengetahuan mahasiswa, khususnya mengenai teknik relaksasi nafas dalam dan kompres air hangat dalam penurunan nyeri dysmenorhea.

3. Bagi Peneliti Selanjutnya. Diharapkan dapat menambah referensi dan sebagai bahan acuan bagi peneliti selanjutnya. 


\section{DAFTAR PUSTAKA}

Ab, R, A., Rowling, M., White, G. and Mason-Jones, R. (2016). Public Sector Supply Chain Management: A Triple Helix Approach To Aligning Innovative Environmental Initiatives. Foresight and STI guidance, 10(1), 43-52. ISSN 1995459X Available from: http://eprints.uwe.ac.uk/28572

Amalia, M. (2015). Hubungan Kecemasan dengan Kejadian Dismenorhoe pada Mahasiswi Tingkat II DIII Kebidanan STIKes YPIB Majalengka Tahun 2015. Majalengka: STIKes YPIB Majalengka

Anwar, M. (2011). Ilmu Kandungan Edisi ke 3. Jakarta: Bina Pustaka Sarwono Prawirohardjo

Arovah, N. I. (2010). Dasar-Dasar Fisioterapi pada Cedera Olahraga. Yogyakarta

Bobak, L, Jensen. (2004). Buku Ajar Keperawatan Maternitas / Maternity Nursing (Edisi 4), Alih Bahasa Maria A. Wijayati, Peter I. Anugerah. Jakarta: EGC

Cakir M., Mungan I, Karakas T, Girisken I, Okten A. (2007). Menstrual Pattern and Common Menstrual Disordes among University Students in Turkey. https://www.ncbi.nlm.nih.gov/pubmed/18045301 diakses tanggal 8 Februari 2017

Calis, K. A. (2009). Dysmenorrhea. Terdapat pada :http://repository.usu.ac.id/bitstream/123456789/31657/4/Chapter\%20II.pdf

Diakses pada tanggal 11 Februari 2017

Dahlan, Syahminan. 2016. Pengaruh Terapi Kompres Hangat terhadap Nyeri Haid (Dismenorea) pada Siswi Smk Perbankan Simpang Haru Padang. Padang: STIKes Ranah Minang Padang

Departemen Kesehatan RI. (2000). Kesehatan Reproduksi Remaja (KRR).Jakarta: Departemen Kesehatan RI

El Manan. (2011). Kamus Pintar Kesehatan Wanita. Yogyakarta: Buku Biru

Ernawati.(2010). Terapi Relaksasi terhadap Nyeri Dismenore pada Mahasiswi Universitas Muhammadiyah Semarang. Seminar Nasional Unimus, 106

Fauziah, Y. (2012). Infertilitas dan Gangguan Alat Reproduksi Wanita. Yogyakarta: Nuha Medika

Kozier. (2010). Fundamental of Nursing: Concepts, Process and Practice. ( $7^{\text {th }}$ Ed). New Jersey: Prenctice-Hall, Inc

Laila, N. N. (2011). Buku Pintar Menstruasi. Yogyakarta: Buku Biru

Mansyur. (2009). Psikologi Ibu dan Anak Kebidanan. Jakarta: Salemba Medika

Manuaba, I. B. G. (2009). Ilmu Kebidanan Penyakit Kandungan dan Keluarga Berencana. Jakarta: EGC

Marianti. (2018). Pengertian Menstruasi. https://www.alodokter.com/menstruasi diakses tanggal 9 Agustus 2018

Marni. (2013). Perbedaan antara Relaksasi dan Komprs terhadap Penurunan Skala Nyeri Haid. Surakarta: Universitas Sebelas Maret Surakarta

Marni. (2014). Perbedaan antara Relaksasi dan Kompres terhadap Penurunan Skala Nyeri Haid. Akper 17 Karanganyar, 1, 91-98. Retrieved from jurnal.akper17.ac.id/index.php/JK17/article/viewFile/10/14diakses tanggal 6 Februari 2017

Morgan, Hamilton. (2009). Obstetri dan Ginekologi. Jakarta: EGC

Muttaqin, A. (2011). Buku Ajar Asuhan Keperawatan Klien dengan Gangguan Sistem Persyarafan. Jakarta: Salemba Medika

Ns Padila. (2012). Buku Ajar Keperawatan Medikal Bedah. Yogyakarta: Nuha Medika

Ns Padila. (2015). Buku Ajar Keperawatan Maternitas. Yogyakarta: Nuha Medika 
Nugroho, T \& Setiawan, A. (2010). Kesehatan Wanita, Gender \& Permasalahannya. Yogyakarta: Nuha Medika

Oktasari. (2014). Perbandingan Efektivitas Kompres Hangat dan Kompres Dingin terhadap Penurunan Dismenorea pada Remaja Putri. Riau: Universitas Riau

Polat A, Celik H, Gurates B, Kaya D, Nalbant M, Kavak E, Hanay F. (2009). Prevalence of Primary Dysmenorrhea in Young Adult Female University Students. https://www.ncbi.nlm.nih.gov/pubmed/18726608 diakses tanggal 8 Februari 2017

Potter, P.A. \& Perry, A.G. (2010). Buku Ajar Fundamental Keperawatan. Edisi 7 Jilid. Jakarta: EGC

Prawirohardjo, S. (2008). Ilmu Kebidanan. Jakarta: Yayasan Bina Pustaka Sarwono Prawirohardjo

Price, S.A. \& Wilson, L.M. (2006). Patofisiologi: Konsep Klinis Proses-proses Penyakit. Edisi 6. Volume 1. Jakarta: EGC

Priscilla. (2012). Perbedaan Pengaruh Teknik Relaksasi Nafas Dalam dan Kompres Hangat Dalam Menurunkan Dismenore pada Remaja SMA Negeri 3 Padang. Padang: Universitas Andalas

Rahayuningrum. (2012). Perbedaan Pengaruh Teknik Relaksasi Nafas Dalam dan Kompres Hangat dalam Menurunkan Dismenore pada Remaja SMA Negeri 3 Padang. Padang: Universitas Andalas

Reeder. (2011). Keperawatan Maternitas: Kesehatan Wanita, Bayi \& Keluarga. Jakarta: EGC

Sari. (2013). Efektivitas Terapi Farmakologis dan Non-Farmakologis terhadap Nyeri Haid (Disminore) pada Siswi Kelas XI di Sma Negeri 1 Pemangkat. Pontianak: Universitas Tanjung Pura

Savitri, R. (2015). Gambaran Skala Nyeri Haid pada Usia Remaja. Bandung:STIKes Aisyiah Bandung

Siahaan. (2012). Penurunan Tingkat Dismenore pada Mahasiswi Fakultas Ilmu Keperawatan Unpad dengan Menggunakan Yoga. Bandung: Universitas Padjajaran

Snyder. M., Lindquist. R. (2002). Complementary Alternative Therapies in Nursing. 4th Ed. New York: Springer Publishing Company, Inc

Sulistyawati, L \& Purwanti, R. (2013). Perbedaan Pengaruh Metode Kompres Hangat dengan Aromaterapi terhadap Penurunan Derajat Nyeri Dismenore pada Remaja Putri. Surabaya: Universitas Airlangga

Tamsuri, A. (2007). Konsep dan Penatalaksanaan Nyeri. Jakarta: EGC

Widyatuti. (2008). Terapi Komplementer dalam Keperawatan. Depok. Universitas Indonesia

Yasui, Y. (2009). A Brainware Signal Measurement and Data Processing Technique for Daily Life Aplication. Journal of Psychologycal Anthropologi. Tokyo: NTT Docomo 